\title{
O ensino público como projeto de nação: a "Memória" de Martim Francisco (1816-1823)
}

\author{
Public Education as the Project of a Nation: \\ the "Memoir" by Martim Francisco (1816-1823)
}

Bruno Bontempi Jr.*

Carlota Boto ${ }^{* *}$

\section{Resumo}

$\mathrm{O}$ artigo trata da Memória sobre a Reforma dos Estudos na Capitania de São Paulo, de Martim Francisco Ribeiro de Andrada, publicada em 1815 ou 1816, e elaborada originalmente para implantação na Capitania de São Paulo. Busca-se proceder à análise historiográfica do documento, considerado no momento histórico de sua elaboração, à luz da mentalidade de sua geração, do gênero da obra e do diálogo que estabelece com o debate iluminista. Tendo recebido parecer desfavorável à sua execução, o texto foi posteriormente apresentado por ele próprio - agora na condição de deputado - à Comissão de Instrução da primeira Assembleia Constituinte do Brasil independente (1823-1824), como proposta de elaboração de um sistema nacional de instrução. Identificam-se no documento os elementos que denotam ter havido apropriação do debate pedagógico da Revolução Francesa. Há uma inequívoca semelhança, inclusive formal, entre esta Memória de

\section{Abstract}

The article deals with the Memoir on the Reform of Education in the Province of São Paulo, by Martim Francisco Ribeiro de Andrada, published in 1815 or 1816, and originally designed for deployment in the Province of São Paulo. The aim is to make a historiographical analysis of the Martim Francisco's document, considered in the historical moment of its development, in the light of the mentality of his generation, the genre of the work and the dialogue established with the Enlightenment debate. Having received an unfavorable opinion about its deployment, the text was subsequently submitted by him - now on the deputy condition - to the Commission Instruction of the first Constituent Assembly of independent Brazil (18231824), now proposing the development of a national education system. Are identified in the document the elements that denote the appropriation of the pedagogical debate of the French Revolution. There is a clear similarity, including formal, between this

\footnotetext{
* Faculdade de Educação, Universidade de São Paulo (USP). bontempi@usp.br

** Faculdade de Educação, Universidade de São Paulo (USP). reisboto@usp.br
} 
Martim Francisco e as Cinco Memórias sobre a Instrução Pública, redigidas por Condorcet, as quais deram suporte teórico ao Relatório da Assembleia Nacional (1791-1792) na França Revolucionária. Palavras-chave: Martim Francisco Ribeiro de Andrada Machado; instrução pública; Condorcet.
Memoir of Martim Francisco and Five Memories on Public Education, written by Condorcet, which gave theoretical support to the National Assembly Report (17911792) in Revolutionary France.

Keywords: Martim Francisco Ribeiro de Andrada Machado; public education; Condorcet.

O presente artigo tem por objetivo refletir sobre a obra Memória sobre a Reforma dos Estudos da Capitania de São Paulo (c.1816), elaborada por Martim Francisco Ribeiro d'Andrada Machado. Trata-se do investimento intelectual desse político e homem de saber brasileiro na expectativa de estruturar um sistema organizado de instrução pública, primeiramente na capitania do Reino português na América, naquele momento sob sua administração, e, quando de sua reapresentação em 1823, para todo o novo Império. Busca-se proceder à análise historiográfica do documento no momento histórico de sua elaboração e à luz da mentalidade de sua geração, do gênero da obra, das representações sociais que compartilha e difunde e da apropriação que faz do debate iluminista e das ideias políticas da Revolução Francesa. A Memória de Martim Francisco dialoga especialmente com o pensamento pedagógico de Condorcet, expresso nas Cinco memórias sobre a instrução pública, publicadas em 1791, e no Rapport et projet de décret sur l'organisation générale de l'Instruction publique, elaborado pela Comissão de Instrução Pública da Assembleia Legislativa da França revolucionária e apresentado em 1792.

Primitivo Moacyr foi o primeiro autor a divulgar em livro a Memória, em seu A Instrução e o Império (Moacyr, 1936). Querino Ribeiro interessou-se pelo documento e sobre ele desenvolveu tese de doutorado em Educação, em 1942. A partir de então, nas raras ocasiões em que historiadores da educação dele se ocuparam, o texto de Martim Francisco foi tratado ora topicamente, para indiciar a preferência pelo método mútuo no oitocentismo brasileiro (Bastos, 1999; Neves, 2003), ora tendo em vista seu breve e infrutífero trâmite na Assembleia Constituinte de 1823, como prova cabal do desinteresse do Estado Nacional pela instrução pública, no que se repete a crítica feita por Moacyr (Xavier, 1980; Ferronato, 2006). Na chave interpretativa cara a autores como Dermeval Saviani (1973) e Casemiro dos Reis Filho (2002), o documento foi interpretado como um "transplante" inadequado às nossas "condições particulares", tendo como função dissimular as "contradições internas" (Xavier, 
1980) da sociedade. A abordagem seguida neste artigo desvia-se dessas tendências, de início, por não tomar o documento no contexto de sua reapresentação, 1823, quando deputados constituintes procuravam elaborar o corpus legislativo de um Estado Nacional Brasileiro, mas no de sua primeira publicação e exame, ou seja, 1815 (ou 1816), quando entre os coetâneos sequer existia um claro projeto de independência (Dias, 2005), portanto, de edificação de um plano nacional de instrução pública. Com isto, resguardamos não só o caráter original reformista de um projeto para a Capitania de São Paulo, então parte integrante do Estado Português, como também evitamos reduzir o seu significativo conteúdo às trivialidades dos debates que suscitou no recinto da Assembleia Constituinte, ou interpretá-lo de modo anacrônico como a expressão de supostas expectativas daquela assembleia e da "aristocracia" pós-Independência, tais como "criar valores sociais e instituições para romper com os preconceitos criados pelo regime escravista no que se refere ao trabalho manual" ou "possibilitar a ascensão dos integrantes da pequena burguesia mercantil que tivessem talentos naturais para serem educados no princípio da individualidade" (Ferronato, 2006, p.128). Por fim, ao tomá-lo em sua integralidade, procuramos deslindar um pensamento pedagógico que se apropria, e não "transplanta" ou é "influenciado", no iluminismo e no liberalismo de Condorcet, e que extrapola largamente os limites de um método de ensino para a escola elementar.

De pronto, descartamos o uso da noção de "influência" do pensamento iluminista e da Revolução Francesa no processo de elaboração do documento e em seu conteúdo. Como aponta Morel (2005, p.41), o termo "influência” tem sido geralmente mobilizado para "definir uma causalidade, uma origem, em geral demarcada por coincidências cronológicas", com a suposição de que os "influenciados receberiam mais ou menos passivamente as 'influências' de ideias ou agentes - ativos". Com isso, são ignoradas ou minimizadas as opções, escolhas e releituras das ideias por parte dos chamados "influenciados" - em outras palavras, a própria ação criativa dos que delas se apropriam. A fim de identificar e explicar as escolhas, opções e releituras de Martim Francisco com relação às obras e ideias que lhe deram suporte para a elaboração da Memória, tomamos como ferramentas de análise as noções de "representações sociais", "apropriação" e "circulação". Lefebvre define a acepção de representações sociais como um conjunto de

normas, modelos, valores, condutas coletivas e imperativas, regulamentos e formas de controle, designados, de maneira ambígua, pelos termos ideologia, cultu- 
ra, conhecimentos etc. Uma análise mais refinada exige que distingamos os degraus da adoção desses elementos externos-internos, na assimilação e na eficácia de seu funcionamento. No grau mais profundo e mais eficaz encontram-se símbolos. (Lefebvre, 1961, p.65)

Roger Chartier, por sua vez, insere a própria inteligibilidade da história no conceito de representação, ancorado na ideia de apropriação. Recordando que os objetos históricos são historicamente construídos e não dados de natureza, sublinha que eles não existem "fora das práticas, móveis, que os constituem, e por isso não há zonas de discurso ou de realidades definidas de uma vez por todas, delimitáveis de maneira fixa e detectáveis em cada situação histórica" (Chartier, 1990, p.78). Assim, a circulação de modelos culturais compreende também a circulação de representações, entendidas como maneiras compartilhadas de pensar. Isso faz com que as sociedades, ao se remeterem a modelos originariamente produzidos no exterior e ao buscar veicular tais referências, como neste caso, produzirão situações de conflito de representações. A ideia de apropriação implica a noção de uma pertença, feita por algum tipo de recepção, mas fundamentalmente pelo efeito de reinvenção dos conteúdos culturais recebidos, havendo, portanto, circunscrições específicas que mapeiam e organizam as ideias em circulação. Quando Martim Francisco lê Condorcet e se apropria de suas ideias, colocando-as em circulação no Brasil do início dos oitocentos, a seu modo está recriando o conjunto de ideias, de vez que qualquer bem cultural se dá mediante filtros intrínsecos à realidade e à história de quem o recebe.

A crença na instrução pública como alavanca de cidadania - como se sabe - foi uma das principais ferramentas teóricas da ilustração europeia. O século XVIII na França, como na Alemanha ou em Portugal entendia a educação como estratégia de construção da democracia; e, portanto, do avanço e do aperfeiçoamento político dos povos. Acreditava-se que uma sociedade esclarecida permite o voto esclarecido. Desse modo, preparar as populações pela escola era uma maneira de construir uma nação mais próspera, mais íntegra e mais poderosa - inclusive em termos internacionais. $O$ discurso da educação era, portanto, falado pela política. Havia uma circulação internacional dessas ideias, que se reproduziam, mas que eram também transpostas e reinventadas. Nascidas no exterior, elas tendiam a - aqui reproduzidas - adquirir novos significados. Para o caso luso-brasileiro, o ideário político-cultural das Luzes ecoou de maneira intensa, principalmente em razão da preponderância da 
língua e da filosofia francesas sobre a elite luso-brasileira. De acordo com Morel,

Não só o francês tornara-se como que um idioma das Luzes, linguagem internacionalizada das elites culturais ocidentais, como também, por outro lado, fazia que a França funcionasse como uma espécie de "metrópole cultural” para estes mesmos grupos letrados que constituíam, também, os quadros dirigentes nacionais de cada país. E aparentemente, nesse momento, tal presença francesa era constituída mais pela rede de comércio do que pela ação, por exemplo, diplomática. (Morel, 2005, p.37)

\section{Martim Francisco, Um ILUSTRAdo brasileiro}

Martim Francisco nasceu, de família endinheirada, na cidade de Santos, a 19 de junho de 1775. Filho de Maria Bárbara da Silva, brasileira, e Bonifácio José de Andrada, português, recebeu em casa sua instrução primária, para depois cursar filosofia, lógica, retórica, moral e língua francesa com frei Manuel da Ressurreição. Entre 1794 e 1798, esteve em Portugal, cursando matemática e filosofia natural na Universidade de Coimbra, onde teria tido contato com a literatura dos iluministas. No final da primeira década do século XIX, Martim Francisco já se tinha tornado Bacharel em Matemática por aquela universidade. De volta ao Brasil, tornou-se Inspetor de Minas e Matas, coronel de milícias e vice-governador da Capitania de São Paulo; mais tarde, ministro da Fazenda (de 1822 a 1823 e de 1840 a 1841), deputado à Constituinte de 1823 e presidente da Câmara em 1831 (Ribeiro, 1945, p.63; Varela; Lopes, 2007, p.951). De acordo com Mendonça, o mais novo dos Andrada "era dotado de relevante inteligência e notáveis dotes oratórios. Sua rispidez e sua intransigência lhe valeram muitos desafetos, mas nunca foi possível abalar o conceito em que era tido, de homem austero, de caráter inquebrantável e de probidade absoluta" (Mendonça, 1963, p.167). Costa sublinha na personagem "a rebeldia do seu temperamento, a rudeza de sua maneira de encarar as coisas, a infatigabilidade de sua intransigência na sustentação dos princípios que serviram de norte à sua conduta" (Costa, 1944, p.258).

No quadro político e ideológico da época, esses princípios são francamente liberais e utilitários. Era por ele compartilhada a crença política de seu irmão José Bonifácio, assim resumida por Raul de Andrade e Silva: "a monarquia, como forma de Estado, mas em termos de liberalismo e constitucionalmente definida, com a finalidade do governo exercido em nome do "bem público"” 
(Silva, 1963, p.50). Martim Francisco, conforme Rodrigues, era "fanático pelas doutrinas de Benjamin Constant, que, no Correio do Rio de Janeiro, era evocado como um dos sábios iluministas, que ensinara ser uma ilusão o poder absoluto" (Rodrigues, 1975, p.5).

De acordo com Morel,

Benjamin Constant defendia um liberalismo em que a força da Sociedade deveria sobrepor-se a Estado, que não seria forte ou centralizador. Sociedade num sentido amplo, seja do ponto de vista da liberdade de comércio e da preponderância do laissez-faire dos grupos econômicos em ascensão até a afirmação mais veemente em defesa da liberdade de expressão e de autonomia do Parlamento. Inútil insistir na importância do pensamento político deste suíço-francês na institucionalização do Brasil Império, sobretudo na Constituição de 1824. (Morel, 2005, p.47)

Costa chega a dizer que a criação do Poder Moderador na Constituição do Império fora obra de Martim Francisco, mas pondera, apoiado em Octávio Tarquínio de Souza, que os escritos de Benjamin Constant, destacadamente o Cours de Politique Constitutionelle, eram então conhecidos "de todos os estudiosos" (Costa, 1944, p.186) - incluindo-se aí o próprio Imperador.

A aderência original às classes dominantes, a fidelidade ao Trono e o desfrute dos privilégios aristocráticos não fizeram dessa geração uma amiga dos regimes democráticos. Como aponta Maria Odila Dias, muito embora criticassem a obsolescência da Corte e do clero, o monopólio comercial e as taxas opressivas impostas pela metrópole, esses homens permaneceram, até que se acentuassem as diferenças e conflitos entre brasileiros e portugueses, inteiramente identificados com a ideia de um grande império português sediado na América, a ser reformado para que fossem superadas a decadência e o atraso com relação ao mundo moderno (Dias, 2005, p.95-98).

Dias aponta que para essa leva de brasileiros formados em Coimbra, Montpellier, Edimburgo, Paris e Estrasburgo, a tendência voltairiana e enciclopedista do iluminismo foi a mais forte referência. Para homens como Voltaire e Diderot, continua Dias, "um incremento da ciência natural, da anatomia, da química e da física experimental” era tido como passo primeiro na reforma da sociedade (Dias, 2005, p.41). Para Dias, produto da penetração do espírito voltairiano e enciclopedista em Portugal é "o fato de, entre os 568 estudantes formados em Direito (maioria significativa no total de 866 brasileiros formados em Coimbra) de 1722 a 1822, ou seja, cerca da metade, 
terem-se formado simultaneamente em Leis e Matemática ou Ciências Naturais" (Dias, 2005, p.42). Martim Francisco, formado em Matemática e Filosofia Natural, compartilhava com José Bonifácio, a quem acompanhou em duas expedições mineralógicas, "esse senso do 'útil' como complemento do verdadeiro, tão conforme ao modo de pensar do tempo" (Liberalli, 1963, p.16). Edgar de Cerqueira Falcão informa que em 1800, José Bonifácio e Martim Francisco fizeram excursão por Extremadura e Beira, na Península Ibérica, apresentando trabalho científico na Academia das Ciências de Lisboa. Em 1820, ambos realizaram viagem de estudos pelo interior de São Paulo, fazendo as observações mineralógicas que resultaram no relatório Viagem mineralógica na Província de São Paulo. (Falcão, 1963, p.152).

Para os homens de ciência de sua geração, como afirmou o viajante e naturalista Alexandre Rodrigues Ferreira, "o grau de aplicação de uma ciência mede-se pela utilidade", ou seja, teriam valor "apenas os estudos de que resultasse alguma utilidade para a sociedade", que fomentassem "o progresso material e das condições de vida dos homens” (cit. em Dias, 2005, p.43-44). Por isso, a exemplo do irmão, Martim Francisco dividiu com as atividades políticas os estudos, tendo participado de viagens científicas (Varela, 2007, p.947) e publicado memórias sobre história natural, notadamente, sobre mineralogia. Como também observa Dias, essa era uma tendência que fazia parte das circunstâncias da elite brasileira:

Elite reduzida, falta de homens capazes, foram em virtude de tais circunstâncias levados a trocar os gabinetes de estudos por ocupações administrativas ou cargos políticos e judiciários ... O que importa, contudo, é ressaltar no Brasil a participação de muitos desses estudiosos na vida pública, decorrente da acumulação de interesses científicos e cargos administrativos e políticos. (Dias, 2005, p.100-101)

Os biógrafos salientam o vasto conhecimento que Martim Francisco possuía de Filosofia e, sobretudo, da filosofia kantiana. Querino Ribeiro destaca o domínio que Martim Francisco tinha da natureza do país, bem como de seus problemas sociais, frutos da uma aguçada capacidade de observação e de perspicácia analítica.

Possuía ele o conhecimento da filosofia mais moderna na época e capaz de orientá-lo quanto aos fins da educação; era senhor de um espírito de observação agudo, justo e imparcial no trato dos problemas que enfrentava; tinha uma experiência vasta, feita 'in loco', quanto às condições gerais da população a que pretendia servir com a aplicação do plano; tinha ainda alguma experiência escolar como 
professor e muita como discípulo; e, finalmente, possuía uma ampla cultura geral feita nos bancos escolares e nas viagens diversas que empreendeu dentro e fora do país, pelas regiões mais diferentes. (Ribeiro, 1945, p.64)

Quando ainda residia em Portugal, Martim Francisco envolveu-se no projeto editorial da Tipografia do Arco do Cego. Criada em 1798, reuniu, sob a orientação de frei José Mariano da Conceição Veloso, nomes como Antônio Carlos, Nogueira da Gama e José Feliciano Fernandes Pinheiro, incumbidos de reunir e traduzir para o português memórias sobre a cultura de gêneros agrícolas, com a finalidade primeira de serem distribuídos entre os lavradores do Reino e da América portuguesa, para que servissem ao melhoramento das culturas. Para Dias, como "a melhoria da produção subentendia uma política de ilustração e de incentivo ao progresso", a Tipografia do Arco do Cego atendia à "finalidade de divulgar conhecimentos de ciências naturais e agricultura, uma vez que razão, natureza e prática deveriam compor forças para o bem da sociedade" (Dias, 2005, p.58-59). De acordo com Varela e Lopes, Martim Francisco incumbiu-se de uma tradução na área de mineralogia, e de outra sobre agricultura (Varela; Lopes, 2007, p.951).

De acordo com José Querino Ribeiro, "nos anos iniciais do século, foi Inspetor das Minas e Matas na Capitania de São Paulo e [nela] se encontrava em 1802, tendo levado a efeito pesquisas de natureza idêntica na região que vai de São Paulo a Sorocaba, em 1803 e pelo litoral de Curitiba, em 1804 ou 1805” (Ribeiro, 1945, p.63). Os escritos de Martim Francisco, no Diário de uma viagem mineralógica pela Província de São Paulo no ano de 1805, apresentam traços característicos do renascimento científico como a descrição, a observação, a coleção e a taxonomia adotados como práticas dos naturalistas viajantes de a partir do século XVIII. De acordo com Oswaldo Munteal Filho, o naturalista luso-italiano Domenico Vandelli, um dos professores recrutados para a reforma dos estudos da Universidade de Lisboa, em dissertação alertou os naturalistas brasileiros para a importância da exploração metódica da natureza e indicou o caráter que esta deveria assumir, tendo em vista o problema da aplicabilidade da ciência (Munteal Filho, 2001, p.40-41). Dentre suas orientações estava a imprescindibilidade da elaboração de diários para o registro de informações, "quanto às circunstâncias do dia, os produtos, lugares, latitude, longitude, riqueza ou pobreza do produto, rumo, vizinhança e circunstância do lugar", além de notas sobre assuntos que variavam da direção dos ventos ao número de habitantes. Varela e Lopes observam, por sua vez, nos diários de Martim Francisco "a preocupação com a descrição detalhada dos elementos 
do mundo natural, intimamente relacionada à fixação do que era verdadeiramente útil” (Varela; Lopes, 2007, p.961). Fundado na crença de que a boa ciência é a que pode resolver problemas práticos, entendia que as "produções naturais minerais e vegetais" deveriam ser transformadas em "recursos naturais" úteis ao Estado português: "como cientista, sua função era semear ideias úteis pela capitania de São Paulo” (ibidem, p.962). Para Dias, relatórios como os de Martim Francisco demonstram a cultura europeia desses intelectuais, "e o desejo de aparecer em plano de igualdade com os estudiosos europeus. Parecem querer a cada página lembrar e afirmar a sua participação na comunidade de sábios e ilustrados de seu tempo" (Dias, 2005, p.77).

A orientação pragmática dos cientistas, é bom que se diga, foi adotada como política de Estado pelo trono português. D. Rodrigo de Souza Coutinho tornou-se ministro de D. Maria I, tendo sido "o articulador político e o responsável pela promoção e consolidação da produção cientificista” (Munteal Filho, 2001, p.69). Interessada na descoberta e no melhor aproveitamento econômico das riquezas naturais da América Portuguesa, a Coroa, aconselhada por ministros ilustrados como D. Rodrigo e o Conde da Barca, estimulava, mediante benefícios como isenção de impostos e concessão de monopólios e cargos, os naturalistas a excursionar, relatar suas observações e experiências em "memórias" para o desenvolvimento de formas de exploração, plantio e melhoramentos de gêneros naturais, que eram endereçadas ao governo português. De acordo ainda com Munteal Filho,

A aventura especulativa portuguesa da segunda metade do século XVIII, e muito especialmente do período mariano e joanino, teve como principal experiência a elaboração de um projeto de confecção de uma História Natural das Colônias. Este esforço voltou-se para o sentido de uma profunda descrição da metrópole e do império colonial ultramarino. (Munteal Filho, 2001, p.34)

D. Rodrigo não só ordenava aos vice-reis e governadores das capitanias que governassem segundo os princípios da razão, em prol do progresso e do aumento das culturas e do comércio, como exigia que se lhe remetessem todas as informações importantes e úteis sobre a colônia. De acordo com Varela e Lopes, os governadores "eram instruídos a levantar, entre outras informações, estatísticas sobre território, população e atividades econômicas; despesas e rendas da Coroa; número de religiosos e rendas e bens territoriais das ordens religiosas; necessidade de efetivos militares nos territórios das capitanias; vegetais e minerais presentes em cada região; e gêneros agrícolas cultivados" 
(Varela; Lopes, 2007, p.953). Esses relatórios, produzidos e encaminhados em profusão ao governo, eram intitulados "memórias", tais como se denominavam os estudos de mineralogia, pesca ou agricultura aos quais os ilustrados luso -brasileiros vinham se dedicando ao menos desde meados do século XVIII, sob a direção da Academia Real das Ciências de Lisboa (Munteal Filho, 2001, p.34-43).

Em 1815, tendo-se licenciado do trabalho de Inspetor Geral das Minas e Matas da Capitania de São Paulo, Martim Francisco transferiu-se ao Rio de Janeiro, onde permaneceu cuidando de seus negócios. Supõe-se, já que o documento original não está datado, que Memória sobre a reforma dos estudos na Capitania de São Paulo teria sido apresentada naquela época. O texto pertence ao gênero das "memórias", portanto, dos escritos que, encomendados pelo governo despótico ilustrado, os homens de ciência luso-brasileiros produziam a fim de fomentar o progresso do império português. Como aquelas, contém ideias e propostas de reforma, fundadas em observações empíricas e objetivas, de sentido utilitarista, e não se confundem com os escritos sociais e políticos como os que, a partir de 1821, José Bonifácio, motivado pela efervescência política, redigiu tratando de temas como a abolição dos escravos, a situação do indígena e a educação do povo, tendo em vista a formação de uma nação livre. Martim Francisco escreve em 1815 ou 1816, quando não há nessa elite um sentimento de nacionalidade com expectativa de independência política; há, é certo, a intenção reformista, o aproveitamento do pensamento ilustrado estrangeiro e o entendimento de que, universalismo à parte, as inovações europeias deveriam ser traduzidas, adaptadas e aplicadas à realidade da colônia (Dias, 2005, p.78).

Esse plano recebeu, na ocasião, parecer negativo de Luiz José Carvalho e Melo. O argumento de Carvalho e Melo era o de que o referido projeto requereria, para ser implementado, a alteração de leis vigentes para todo o país; e que, portanto, não faria sentido restringir sua aplicação a uma única capitania. Carvalho e Melo reconhece que o projeto abarcava um plano de expansão da instrução pública para todas as classes sociais, nos moldes do que se fazia nos países mais avançados do mundo, facultando a todas as classes pelo menos os três primeiros anos de escolarização. Além disso, o plano destacar-se-ia pela maneira como expunha as dimensões logísticas e operacionais do funcionamento das escolas: como os professores seriam recrutados, quais os métodos do ensino a ser ministrado, quais as doutrinas e serem ensinadas etc. Ressalta também a importância de terem sido abordados aspectos relacionados à formação do espírito e do coração dos cidadãos, para que, "polindo o 
entendimento e enriquecendo-o de conhecimentos úteis, e aprendendo os sólidos ditames da moral, se fizessem homens de probidade e bons e honestos cidadãos e hábeis para seus diversos destinos na vida social” (Melo, 1945, p.111).

A objeção do parecerista, portanto, não dizia respeito às dimensões pedagógicas da proposta; mas, sim, ao seu caráter político: não haveria - do ponto de vista do relator - justificativa para um projeto como aquele ser implantado em apenas uma Capitania do Reino "sem se generalizar em todas as partes da monarquia e, para assim acontecer, é necessário revogar Leis, mudar a forma da educação moral e literária da nação, e derrubar todo este edifício" (ibidem, p.112). Tal empreendimento exigiria ainda a realização de exames unificados por meio da legislação geral. Haveria, contudo, dificuldade de encontrar professores suficientemente capazes e preparados por seus conhecimentos, em virtude dos singelos ordenados a eles oferecidos. Enfim, por tais razões, datado de 15 de novembro de 1816, o parecer conclui que não seria conveniente implantar na Capitania de São Paulo a reforma dos estudos proposta pelo projeto de Martim Francisco, a despeito dos méritos do documento e de seu autor.

\section{INSTRUÇÃO PÚBLICA COMO OBRIGAÇÃO \\ DA POLÍTICA: O PRIMEIRO GRAU DE INSTRUÇÃO}

A Memória sobre a reforma dos estudos da Capitania de São Paulo é dividida em capítulos, dos quais o primeiro versa sobre a necessidade de uma instrução geral e sobre a insuficiência do sistema então vigente. A instrução pública é apresentada como dever do soberano perante seus vassalos, como obrigação da sociedade política ou do governante frente aos governados, em proveito de ambos. A remissão a Condorcet é indisfarçável:

A instrução pública, igual e geralmente espalhada por todos os membros de qualquer Estado, nivela pouco mais ou menos suas faculdades intelectuais; aumenta sem prejuízo a superioridade daqueles que a natureza dotou de uma organização mais feliz; aniquila esta dependência real, triste monopólio que as luzes de uma classe exercitarão sobre a cega ignorância da totalidade; destrói a desigualdade que nasce da diferença de sentimentos morais; facilita a cada um o gozo dos bens que a sociedade confere; corta pela raiz os males e brandões da discórdia com que a ignorância em diferentes épocas tem abusado o mundo e dos quais estão cheios de páginas a história; e finalmente conspira a promover a prosperidade 
dos Estados e a torná-los firmes e estáveis pela reunião das forças morais com as físicas. (Machado, 1945, p.93)

Inspirado em Condorcet, crê na instrução pública como um dever de Estado, estabelecido como um contrato com o cidadão, com proveito recíproco. Suas consequências são benéficas: quando estendida aos cidadãos de todas as idades, nivela as faculdades intelectuais naturalmente diversas, elimina a dependência de uma classe com relação a outra, agindo contra a desigualdade entre os homens, promove a prosperidade dos Estados. Martim Francisco destaca que a sociedade política deverá ser habilitada na totalidade de seus membros, iluminando-os e afastando-os do erro e da ignorância. Aproximar as novas gerações do contato com o conhecimento seria, assim, um dever civilizatório. Martim Francisco examinou o texto de Condorcet e dele empresta algumas expressões. A ideia de preservação do erro e da ignorância, a caracterização da escola como templo da verdade, tudo isso literalmente consta das Memórias de Condorcet. A noção de um aperfeiçoamento progressivo que pode ser firmado pelo conhecimento ministrado em todas as idades também é uma ideia que se pode localizar no plano de Condorcet.

Assim como o legislador francês, Martim Francisco divide em três graus os níveis de sua instrução; dizendo - como aquele - que isso se deve ao "tempo que cada moço pode empregar no estudo sem prejuízo de seu estado, à força da sua atenção; à extensão e tempo de sua memória; e finalmente à facilidade e precisão de sua inteligência" (ibidem, p.95). Encontra-se nisto de acordo com Condorcet, posto considerar que a criança e o jovem progridem gradualmente em suas operações mentais e que, por isso, nem todas as matérias podem ser ensinadas a todas as idades, nem as matérias ensinadas por um mesmo método podem ser aprendidas por todos durante o mesmo número de anos. Esse trecho, assim como outros, é quase uma cópia do texto de Condorcet, cujas palavras são as seguintes: "A soma dos conhecimentos que convém dar a cada homem deve, por consequência, ser proporcional não somente ao tempo que ele pode dedicar ao estudo, mas também à força de sua atenção, à extensão e à duração de sua memória, à facilidade e à precisão de sua inteligência" (Condorcet, 2008, p.34). Estabelecem, ambos, uma gradação de estudos, não conforme a ordem lógica dos conteúdos, mas de acordo com a maturidade do educando. Trata-se, como em Rousseau, de conduzir a criança para que atinja a razão.

O primeiro grau de instrução comum deveria durar 3 anos - dos 9 aos 12 . Essa seria uma época em que "os filhos dos pobres podem, sem algum prejuízo, 
consagrar diariamente algumas horas ao estudo" (Machado, 1945, p.96). O autor reconhece ser curto o período de 3 anos; mas argumenta, já procedendo a uma adaptação, que "nos países quentes, sendo mais prematuro o desenvolvimento físico e este andando de par com o desenvolvimento intelectual, o menino mais cedo se desenvolva, com mais facilidade, em menor tempo aprende um maior número de verdades" (ibidem, p.96).

Em cada escola haverá uma só sala em que o professor ministraria aulas para três classes; com a justificativa de que os alunos, "não mudando de mestre, adquirem com o tempo unidade de instrução e unidade de caráter" (ibidem, p.96). Seria, pois, uma única sala para cada escola, repartida em três classes hierarquicamente seriadas e graduadas. E, "desde modo, o professor, coadjuvado pelos discípulos mais adiantados e de sua escolha, pode manter a ordem em todas, sem fazer cargo a estes de cuidados superiores ao seu alcance" (Machado, 1945, p.96).

Há outros aspectos da Memória de Martim Francisco que foram objeto de consideração de Condorcet. Ambos sugerem, por exemplo, que se ensine paralelamente a ler e a escrever; o que era inovador para a época, especialmente em se considerando os modelos e as práticas então existentes, mediante os quais o ensino da leitura antecedia o ensino da escrita - ocasionando um aprendizado extremamente lento para a aquisição da linguagem escrita; ambos sugerem que o ensino deverá ter como âncora um compêndio escrito especialmente para esse fim. Esse mesmo compêndio deveria conter:

$\left.1^{\circ}\right)$ palavras isoladas e sem nexo, que o menino possa compreender e das quais o mestre lhe possa dar uma inteligência mais precisa; $2^{\circ}$ ) um número de frases simples, ou sentenças claras, proporcionadas à sua capacidade e que exprimam alguns destes juízos, que ele costuma diariamente formar, ou então algumas observações sobre objetos, que habitualmente vê, de feição que nelas descubra a expressão de suas próprias ideias, o que seria para ele um exercício encantador. Nessa ocasião pode o mestre explicar algumas das primeiras noções de gramática de nossa língua; $3^{\circ}$ ) curtas histórias morais, despidas de toda a máxima, ou reflexão, próprias a fazê-lo atentar sobre os primeiros sentimentos que experimenta. (Machado, 1945, p.97)

Depois disso seriam feitas descrições de animais e de vegetais, em preocupação que denota a inclinação naturalista de Martim Francisco e de sua geração ilustrada. Finalmente, haveria "a exposição do sistema da numeração com os caracteres, que designam os números, e o método de com eles 
representar todos, escrevendo em cifras qualquer número exprimindo por palavras e inversamente" (ibidem, p.97). A valorização dos animais tem a seguinte justificativa em Martim Francisco: "a compaixão pelos animais tem o mesmo domicílio que a primeira [compaixão pelos homens]; ambas nascem dessa dor e dever irrefletidos, excitados em nós pela vista, ou pela lembrança dos sofrimentos de outro ser sensível" (ibidem, p.97). De fato, o texto aqui é muito próximo do que dissera Condorcet, cujas palavras são as seguintes: "tanto uma quanto outra [piedade para com os animais e para com os homens] nascem dessa dor irrefletida e quase orgânica, produzida em nós pela visão ou pela lembrança de sofrimentos de outro ser sensível" (Condorcet, 2008, p.76). Nesse caso, os dois políticos prestam seu tributo à noção de piedade natural desenvolvida por Rousseau em Discurso sobre a origem e os fundamentos da desigualdade entre os homens. Ali, menciona a "repugnância inata de ver sofrer seu semelhante" (Rousseau, 1983, p.253), dizendo que esse primeiro afeto pelo outro consiste em uma "disposição conveniente a seres tão fracos e sujeitos a tantos males como o somos; virtude tanto mais universal e tanto mais útil ao homem quando nele precede o uso de qualquer reflexão". As ideias circulavam, portanto, entre pensadores que se liam, e assim se reproduziam. Havia nitidamente intertextualidade na construção do discurso sobre a sociedade, sobre a infância e sobre a escolarização.

Relativamente aos estudos do segundo ano, Martim Francisco explicita diretamente o desenvolvimento dos primeiros movimentos da piedade, que se tornam para a infância o primeiro exercício de humanidade. O livro de leitura principiará por histórias morais. O menino será, a um só tempo, treinado na leitura e formado na moralidade, e caberá ao mestre apenas "desembrulhar o fio" e "mostrar a vereda"; porque "as leis imperativas de nossa vontade não nascem da vista dos objetos sensíveis, mas da reflexão de cada indivíduo sobre seu sentimento íntimo, sobre o seu eu interno" (Machado, 1945, p.98).

Dos princípios morais - no terceiro ano de instrução - seria desdobrado o aprendizado das lições de civismo. Destacar-se-ia a necessidade de um código único e comum de moralidade, o qual deveria reger todas as pessoas. Daí se passa

à exposição da organização constitucional portuguesa e da natureza dos poderes que a mantêm; a um resumo da história natural do país e sua aplicação à agricultura e artes mais comuns; ao aperfeiçoamento dos métodos de agrimensura, o que fortifica o hábito da aritmética e geometria. Finalmente, à exposição elemen- 
tar de alguns princípios de física e à explicação dos efeitos das máquinas mais simples e de mais uso na Capitania. (ibidem, p.99)

A Memória de Martim Francisco destaca a necessidade de buscar criteriosamente o método para cada modalidade de ensino a ser ministrada nesse primeiro grau de instrução. O método é apresentado como um elemento absolutamente atrelado às finalidades da educação: encerrar os conhecimentos mais precisos, formar ideias justas, fortalecer as faculdades mentais mediante continuado exercício e, finalmente, "habilitar os moços para uma instrução mais extensa e completa” (ibidem, p.99). Os sentimentos morais seriam despertados por meio de histórias interessantes; o estudo da geometria seria estimulado mediante o entretenimento das crianças no recorte de figuras; a história natural seria explorada à luz da apresentação de objetos 'aos olhos'... Desse modo, todas as recomendações relativas aos métodos de ensino prendem-se à busca de semear "de prazeres o caminho da instrução" (Machado, 1945, p.100). Pela mesma lógica, os castigos estariam banidos do sistema aqui apregoado. A escola deixaria de ser um cenário de terrores, regida por um Deus cruel e seus carrascos coadjuvantes. Essa escola, que gangrenava o corpo político, seria, pela reconstrução do método, um espaço regenerado que abria ao estudante as portas do conhecimento. À família caberia dar também o devido "encorajamento ao estudo", posto que um fator imprescindível de estímulo da meninice reside exatamente no "desejo de ser aprovado e amado por seus progenitores" (ibidem, p.100).

\section{A FORMAÇÃo DE FUNCIONÁRIOS DO ESTADO: \\ O SEGUNDO GRAU DE INSTRUÇÃO}

O segundo grau de instrução duraria 6 anos - portanto, dos 12 aos 18 . Corresponderia a um "estudo elementar de todas as matérias relativas às diversas profissões da sociedade, estudo que deve sempre proporcionar-se ao gradual desenvolvimento das faculdades naturais dos discípulos e aos serviços de segunda ordem necessários ao bem do Estado" (Machado, 1945, p.100). Tratava-se - como se pode constatar - do preparo do corpo de funcionários do Estado, bem como dos empreendedores de que teria necessidade a economia do país, no que se encontra de acordo com a mentalidade que presidira as reformas pombalinas da instrução pública (Carvalho, 1978, p.189-191). No primeiro grau de instrução, "deram-se de mistura os elementos de todos os conhecimentos necessários ao uso da vida” (Machado, 1945, p.100). No 
segundo, pretendia-se estabelecer as linhas de demarcação desses mesmos conhecimentos, separando as matérias e aprofundando o estudo de cada uma. Aos 18 anos, com sua formação consolidada nesse segundo grau, o rapaz terá suas faculdades plenas de vigor e de força; e poder-se-á inclinar "por esta ou aquela profissão da vida" (ibidem, p.101). O documento diz também que, chegado esse tempo, o jovem saberá em qual ciência deverá se aplicar. Aqui, todavia, a escolarização adquire claramente o caráter do ensino seriado, com uma temporalidade clássica do horário escolar; com a subdivisão escolar do espaço físico no recorte das salas de aula: cinco professores para o ensino das matérias; cinco salas de aula. Como diz o documento de Martim Francisco,

Não é possível manter neste segundo grau a devida unidade de caráter da instrução, porque a divisão de matérias pressupõe a divisão de mestres; mas então já ela não é tão necessária, como no primeiro degrau da vida, em que se faz preciso dar assento e estabilidade a paixões sem cessar renascentes. Demais um caráter já meio formado pelos sentimentos morais desenvolvidos nos primeiro curso de três anos e as primeiras luzes nele adquiridas juntas à boa escolha de mestres, destruirão em parte a versatilidade natural dos moços, e servirão de tocha para a boa direção de suas paixões. (ibidem, p.101)

As matérias do segundo grau seriam gramática latina; língua francesa; metafísica, lógica e moral; "ciências físicas fundadas na observação e experiência"; matemática e cálculo; história e geografia; "retórica ou a arte de exprimir ideias" (ibidem, p.101). Ao justificar o elenco, pela primeira vez Martim Francisco cita Condorcet:

Quanto à metafísica e à moral, direi, como dizia Condorcet nos últimos momentos de sua vida, que, sendo manifesta a imperfeição da análise das faculdades intelectuais e morais do homem, cumpre dar uma nova análise crítica dessas mesmas faculdades, refazer a ciência do entendimento humano desfigurada pelos sensualistas, banir esta metafísica dos sentidos, que colocara o interesse e todas as paixões do trono da moral. (Machado, 1945, p.102)

No estudo da história e da geografia, é necessário - diz o texto - "seguir a ordem dos tempos" (ibidem, p.103). O discípulo será instado a aprender a "ordenar no espaço e no tempo, os fatos e observações diversas que lhe forem transmitidos, habituar-se-á a abarcar suas relações e a criar para si uma filosofia da história" (ibidem, p.103). Isso não acontece com o mero estudo do que chama de fatos isolados, "que, espalhados nas diferentes páginas de um livro, 
instantaneamente se riscam da memória”. Para fixar o conhecimento na memória, o estudante deverá conservar o que aprendeu, mediante a possibilidade de construção de "quadros em seu pensamento". Para formar a habilidade da escrita, o autor recorda que a retórica dos modernos está na arte de escrever os discursos. Portanto, não se trata mais de construir textos para "persuadir e seduzir os povos pelo dom da palavra”. A sociedade da cultura impressa requer o preparo de outras habilidades, a saber: "clareza, método e simplicidade; desenvolver as razões com ordem e precisão, evitando, de um lado, a negligência ou afetação, e, de outro, a exageração e o mau gosto" (ibidem, p.103).

Sabe-se que a crença de Condorcet nos progressos do espírito humano está absolutamente atrelada à sua fé no conhecimento verdadeiro. Daí sua recusa a qualquer nível de retórica que não seja firmado a partir do reconhecimento da verdade. A eloquência, por si, para ele, poderia ser fator de erro, de engano e mesmo de superstição. Martim Francisco aqui copia nitidamente a ideia do revolucionário francês:

Seria, além disso, bom que o mestre ensinasse a arte de reunir em um todo as ideias, de as encadear e classificar, já escrevendo com elegância e nobreza, já evitando defeitos que a natureza às vezes coloca a par das grandes qualidades de espírito; que finalmente exercitasse seus discípulos com exemplos no modo de desembrulhar o erro dentre os prestígios da imaginação, ou o babélico das paixões, e de abarcar a verdade sem exagerá-la. Desse modo, estou certo que os homens nascidos para a eloquência se-lo-ão para a verdade, e aqueles a quem a natureza recusou igual talento, saberão inda agradar, fazendo amar a razão. (Machado, 1945, p.103-104)

\section{O LUgAR PÚBlico de MESTRES Vitalícios}

Martim Francisco dedica um capítulo de sua Memória a tratar dos mestres e dos compêndios escolares. Estes últimos, destinados principalmente para o primeiro grau de instrução, e abarcando "princípios de verdade geralmente reconhecida ... devem ser compostos debaixo da vigilância e inspeção do Estado, porque desta forma sua doutrina nunca será desnaturalizada pela superstição ou negligência" (ibidem, p.104). O texto indica, ainda, a possibilidade de tais obras serem compostas pelos próprios mestres ou por pessoas interessadas "nesse gênero de trabalho em benefício da pátria" (ibidem, p.104). Caso isso não ocorra, deverá haver pelo menos a tradução de compêndios escolares, aqueles "que há nas outras nações cultas, especialmente a alemã, que mais se 
tem assinalado nesta espécie de instrução" (ibidem, p.104). Haveria, para a escolha dos livros, uma “corporação de pessoas literatas e sábias", encarregadas de proceder ao exame das obras. Já para o segundo grau, o texto prevê que fique sob o encargo do próprio mestre a escolha dos livros dos quais se valerá, "fazendo-os, traduzindo-os, ou aproveitando os que há na nossa língua" (Machado, 1945, p.104).

Para a escolha dos mestres, Martim Francisco sugere que, após os exames que avaliam conhecimento e capacidade, fossem escolhidos três mestres para cada cadeira. Dos três mestres escolhidos, apenas um seria aprovado pelo diretor dos estudos em nome do Soberano. O autor destaca também seu anseio quanto à criação de Sociedades Literárias: “estabelecimentos que, pela grande massa de luzes, que procuram e disseminam, são da maior necessidade nesta e outras capitanias" (ibidem, p.104). Quando forem criadas tais sociedades, ficará a cargo delas a proposta de três mestres para cada cadeira, dentre os quais o Diretor dos Estudos escolherá um, a ser aprovado pelo Soberano.

Nessa passagem, o espírito - mais do que a letra - do texto de Martim Francisco aproxima-se muito daquele de Condorcet, quando este último expõe as razões de ser da Sociedade Nacional das Ciências e das Artes. Os membros da Sociedade Nacional elegeriam a si próprios, escolhendo seus pares dentre os homens ilustrados - que o texto de Condorcet chama de "sábios ou homens de letras" (Condorcet, 1943, p.71).

Assim, todos os que cultivam as ciências, os que as amam, poderão, conhecendo os concorrentes, apreciar a eleição e exercer sobre a Sociedade a única censura verdadeiramente útil - a da opinião, armada exclusivamente com o poder da verdade. A classe inteira, composta de sábios de muitos gêneros, que decidem segundo a fama e segundo o seu critério, reduzirá esta lista a um número; por fim, a seção escolherá; e a responsabilidade recaindo então sobre um número pequeno de homens que apenas julgam dos talentos que devem conhecer bem, será suficiente para contê-los.

Cada classe da Sociedade Nacional elege da mesma forma os professores dos liceus, cujo ensino correspondia às ciências que são objeto dessa classe. Os professores dos liceus nomearão os dos institutos, mas a municipalidade terá o direito de reduzir a lista dos elegíveis. Quanto aos professores das escolas primárias e secundárias, a lista dos elegíveis será formada pelos professores dos institutos do distrito, e a eleição pertencerá, para os primeiros, à corporação municipal do lu- 
gar em que exista a escola e, para os últimos, à assembleia dos pais de família do respectivo distrito. (Condorcet, 1943, p.71-72)

Martim Francisco assinala o papel que as Sociedades Literárias possuiriam, posto que possibilitariam "esperar mais luzes e imparcialidade na nomeação dos mestres” (Machado, 1945, p.104). Chega a dizer que sua própria existência dispensaria a realização de exames públicos, posto que haveria um crivo crítico de especialistas capaz de referendar o mérito na medida justa.

Porque então, generalizadas as luzes, os homens de mérito são conceituados em seu justo valor pela opinião pública, e logo o juízo de homens sábios e imparciais deve ser anteposto à regra inserta de um exame público que apenas pode decidir de uma qualidade, mas nunca do todo das qualidades diversas que se requerem num mestre. (Machado, 1945, p.105)

Quais seriam, todavia, os atributos necessários para ser professor? Diz o texto que a tarefa de mestre supõe hábito e gosto por vida sedentária e pela rotina. Para sua nomeação, não bastariam aptidões intelectuais. O professor nomeado deveria, além da demonstração de conhecimento teórico, revelar aptidões de caráter, sendo, a um só tempo, firme e zeloso, paciente e doce, digno e dotado de "um espírito exato e vivo flexível e metódico" (ibidem, p.105). Finalmente, o professor precisará ser assíduo, e não deverá participar de nenhum tipo de associação, nem opinar sobre a distribuição de cadeiras vacantes. É preciso que a própria rotina de vida do mestre revele o tom de sua abnegação e dedicação ao magistério como interesse precípuo, de modo que não seja tentado pela sedução da intriga ou da ambição.

Martim Francisco recomenda estabilidade para os mestres em suas cadeiras; já que "a utilidade pública exige que empregos de uma longa e penosa preparação tenham uma espécie de perpetuidade” (ibidem, p.105). Reconhecendo a dificuldade da profissão, especialmente quanto à necessidade de se dominar ramos diversos dos conhecimentos humanos, o autor dirá que “o emprego do mestre deverá durar 20 anos, espaço já grande na vida de um homem, e suficiente para execução dos trabalhos que empreendeu a bem da instrução pública e não superior à conservação de sua força, capacidade e gostos" (ibidem, p.105). Tal medida faria justiça à "curteza da vida"; embora depois de concluídos esses 20 anos, o mestre poderia ser mantido em exercício, caso fosse de seu interesse. De todo modo, a previsão é que, caso cumpra aquele tempo, o mestre possa ser "jubilado com seu ordenado por inteiro" (Machado, 1945, p.106). No caso de sua morte, sua mulher e seus dependentes 
teriam direito a uma "pensão proporcional ao tempo de serviço". A justificativa era a de que "homens que bem mereceram da pátria e condenaram parte de sua vida a uma profissão tão penosa e útil têm irrefragável direito a uma recompensa, que os indenize de todos os sacrifícios" (ibidem, p.106). Aqui, a representação da imagem do professor à luz de uma missão, dotada de vocação, é acoplada nitidamente à desvalorização social da profissão.

\section{O Diretor dos Estudos E A INSPEÇÃo das ESCOLAS}

Martim Francisco delega a um Diretor dos Estudos a tarefa de organização da instrução pública. Diz ele que "todo estabelecimento ou instituição pública pressupõe um chefe ou ecônomo, qualificado por sua representação e probidade e versado em todas as matérias que fazem objeto deste plano" (ibidem, p.106). Sob seus cuidados ficaria a direção de um conjunto de escolas em uma dada região. Esse diretor será, naquele primeiro momento, nomeado pelo Soberano; depois, preferencialmente indicado pelas Sociedades Literárias. Caberá a ele, além de gerir as escolas sob sua responsabilidade, proceder ao aumento da biblioteca. Quando os professores faltarem, o diretor assumirá suas classes, quando as salas de aula não estiverem devidamente conservadas, caberá a ele providenciar sua reparação. O diretor, além disso, nomeia e destitui professores. E, no final de cada trimestre, deverá presidir a Congregação dos professores da cidade, cujo objeto é a discussão do ano letivo de cada mestre, "do número dos discípulos, seu progresso, ou adiantamento, para poder, com conhecimento de causa providenciar o que for mister, e corrigir paternalmente aqueles moços que se desviarem do cumprimento de suas obrigações" (Machado, 1945, p.107).

O Diretor dos Estudos terá em suas mãos - fornecido pela municipalidade - um certificado de exercício dos mestres, com suas atividades, bem como a lista dos alunos de cada um, o adiantamento desses alunos. Esse registro faz com que ele possa saber quais visitas deverá fazer com maior frequência, quais as escolas com maiores problemas, quais os professores mais bem-sucedidos, onde eventualmente podem ocorrer abusos etc. Com essa documentação em seu poder, o diretor inspecionará as escolas e aulas públicas sob sua supervisão.

O documento recomenda também aspectos pragmáticos da organização cotidiana do ensino. Ao longo do ano letivo, o professor deverá ter nove listas com os nomes dos seus alunos - uma para cada mês do curso (que ocorre de março a novembro). Em cada lista, "assentará diariamente as falhas e estado de adiantamento deles" (Machado, 1945, p.108). O registro posteriormente 
será apresentado à Congregação ou ao Diretor dos Estudos, para que se possa comprovar a avaliação da frequência ou da aplicação. No segundo grau, os alunos serão confrontados com três questões sobre a matéria ministrada: "será o meio de entreter os estudantes nas horas vagas, de os habilitar a escrever e de arraigar melhor as ideias adquiridas" (ibidem, p.108).

Para o estudante de segundo grau ser promovido de um ano para o outro, ele deverá ser aprovado em "exame público, no qual se conceitue sua aplicação e progresso: o método dos exames, admitido para os estudantes, tem por fim acostumá-los a falar em público e a dar-lhes certas facilidades, que é de desejar em certas idades" (ibidem, p.108). Não haverá, todavia, exame na passagem dos estudos do primeiro para o segundo grau. Só deverá passar por exame, nesse caso, aquele estudante que se julgue, por alguma razão, lesado pela avaliação de seu mestre ou "os estudantes de escolas particulares que quiserem passar para as públicas” (ibidem, p.108). Martim Francisco oferece detalhes do ritual proposto para a escolarização:

No primeiro dia letivo do ano, cada um dos professores do segundo grau, à exceção dos de língua latina, recitará um discurso que contenha a descrição das matérias que vai ensinar, a história ou a ciência, ou arte, como por exemplo, seu nascimento, seus progressos na ordem dos tempos, suas utilidades, etc., e os escritores que mais influíram para o adiantamento dela. A curiosidade do moço excita-se e desperta-se por tais discursos; ele começa a apaixonar-se por aquilo, que vai fazer o objeto de suas meditações e trabalhos. Além disso, nos casos difíceis, adquire gosto e crítica na escolha dos sábios, cujos escritos deve consultar. (Machado, 1945, p.109)

Em cada vila da Capitania de São Paulo onde se pretenda criar uma escola - conclui o texto - é fundamental haver, pelo menos, "uma sala destinada para o ensino público" (ibidem, p.109). Já nas cidades, deverá haver mais outras três salas para que possam ser dadas mais lições, para que possa haver também uma delas "destinada para a sala das congregações, e nela haverá uma estante e uma mesa decente com gavetas para guardas as listas mensais, livros de exames e outros papéis" (ibidem, p.109).

\section{CONSIDERAÇÕES FINAIS}

Em post-scriptum da edição em boletim da tese que defendeu sobre a Memória, Querino Ribeiro relata que na ocasião de sua defesa pública um dos 
examinadores, o professor Paul Arbousse Bastide, observara que Martim Francisco havia-se apropriado das cinco Memórias de Condorcet, sem conferir-lhe o devido crédito. Vários trechos dessa obra, dizia ele, teriam sido simplesmente transcritos, evidenciando o plágio. Em resposta, Querino Ribeiro explicita que "Martim Francisco não fez uma tradução servil pura e simples; fez uma adaptação de um plano de ensino projetado por um revolucionário numa república ultrademocrática, com uma tradição de cultura multissecular, para um país novo, semicolonial, governado por uma monarquia ultra-absolutista" (Ribeiro, 1945, p.88). Diz ainda que Condorcet dirigia-se a cidadãos e que Martim Francisco dirigiu-se a súditos. Condorcet vale-se em seu trabalho do ideal da "igualdade" como pilar que alicerça o significado de uma instrução universal e única; ao passo que "Martim Francisco não faz uso uma só vez dessa palavra" (ibidem, p.89). Bastide, na referida banca, teria dito acreditar "haver intenção evidente, da parte do velho Andrada, de camuflar o pensamento revolucionário" (ibidem, p.89). Ribeiro, defendendo da acusação de má fé o brasileiro, destaca que o parecer de Carvalho e Melo já assinalara que o texto explorava o corpo doutrinário de renomados escritores da época. Plágio ou não, a obra de Martim Francisco permite identificar os elementos que marcam a apropriação e "adaptação" das ideias revolucionárias de Condorcet para o contexto reformista do iluminismo luso-brasileiro.

Para a confecção de sua Memória, Martim Francisco valeu-se, de fato, das Cinco memórias sobre a instrução pública escritas por Condorcet. Mas não foram elas sua única referência. Há pontos comuns e cópias de trechos, mas há outros em que a obra de Martim Francisco se distancia por completo dos escritos de Condorcet. Querino Ribeiro diz que a maior falha da Memória de Martim Francisco nada tem a ver com isso, mas consiste no fato de não haver explicitado a distribuição das escolas. De fato, o número de escolas apresentado como necessário para cada vila ou cidade parece absolutamente insuficiente para quem pretendia estender a todas as crianças as oportunidades sociais de instrução. Martim Francisco, como Condorcet, condena as associações de mestres, o que seria um ponto frágil de sua proposta. Querino Ribeiro recorda que a ausência do princípio da obrigatoriedade escolar é outro aspecto emprestado de Condorcet. Tratava-se, talvez, de "excessiva fé na oferta de escolas gratuitas" (Ribeiro, 1945, p.78). Desconsiderava-se a possibilidade de haver resistência dos pais a enviarem seus filhos à escola.

Querino Ribeiro enfatiza que um dos pontos que conferem solidez ao projeto de Martim Francisco é o fato de haver nele uma clara preocupação com a organização curricular: com a unidade e sequência dos níveis da formação, 
mediante o encadeamento do primeiro para o segundo grau da instrução. Essa divisão do curso em estágios hierarquicamente firmados seria um avanço, dado que representaria o planejamento de uma nova estrutura pedagógica. Martim Francisco teria sabido captar o "movimento mundial de maior difusão do ensino pelas diversas camadas da população" (ibidem, p.82). Mais do que isso: teria sido perspicaz ao perceber a força da renovação cultural para a construção da nacionalidade. Trata-se de um pensamento de época, que dialoga com matrizes teóricas e com exemplos de ação. Mas é preciso também olhar para ele, buscando ali as tensões e os indícios do que poderia haver de original.

As semelhanças entre os dois projetos não obscurecem as distinções políticas entre as propostas. Martim Francisco fazia uma apropriação muito específica do pensamento de Condorcet, em virtude do lugar institucional que ocupava na administração do Reino e, especialmente, em virtude de seu compromisso com a Monarquia. As coincidências na história de vida de ambos os autores e, curiosamente, no destino de seus escritos, também são indicativos do que os familiariza e do que distancia as duas realidades políticas. Condorcet e Martim Francisco eram homens de saber e de política e haviam-se destacado por seus interesses no Direito e na Matemática. Outra similaridade é que ambos os projetos não chegaram a ser aplicados em sua época: o de Condorcet foi abandonado com o estabelecimento da Convenção e em função de outros assuntos; quando a causa da educação voltou ao plenário, outro projeto passou a ser discutido; o de Martim Francisco foi por duas vezes silenciado: na primeira, um parecerista barrou o projeto, apoiado principalmente no centralismo e na uniformidade da política imperial; na segunda, as turbulências do Parlamento nacional impediram o prosseguimento das discussões sobre o ensino. O percurso dos dois autores após o esquecimento de seus projetos, por sua vez, indica a diferença em seus modos de pensar o social: Condorcet morreu na prisão, vítima da radicalidade jacobina em uma Revolução que propunha subverter a ordem instituída; já Martim Francisco, cassado e exilado em 1823, retornaria ao Brasil apenas 5 anos depois, para ocupar posições de prestígio na política.

Liberais, não defendem a escolarização geral obrigatória, mas o acesso à educação por todos os cidadãos; o Estado se encarregaria da organização do sistema educativo, mas não de sua gerência (Condorcet); o Estado não é o promotor exclusivo da instrução, requerendo o apoio do ensino livre por particulares (Martim Francisco). Em Condorcet o liberalismo é mais genuíno e franco: ele se recusa a manter os privilégios das ordens, dimensão que o regime de padroado vigente em Portugal não permitia, o que explica a supressão desse 
tópico na Memória de Martim Francisco. Outro aspecto a contrastar com a lógica revolucionária de Condorcet é a necessidade de se estender a instrução para as mulheres. No texto de Martim Francisco, esse aspecto não é acentuado, indicando mais uma vez o caráter moderado do pensamento da elite imperial brasileira.

É preciso, além disso, reafirmar que a apropriação do pensamento pedagógico ilustrado entre nós tem o filtro do Iluminismo português, peculiarmente reformista, progressista, nacionalista, regalista e católico (Carvalho, 1978, p.27), com inegável traço "pragmático". O estrangeirado Antonio Nunes Ribeiro Sanches, principal protagonista no tocante ao temário pedagógico português, reportava-se em suas cartas à necessidade de controle das escolas por parte do Estado, com a finalidade de produzir um tipo de sujeito civil, capaz de atender aos interesses do Reino. A juventude aprenderia a ser cortês e a ser obediente. Deveria haver livros para uso nas escolas para introdução de preceitos de organização da vida civil. O resultado disso era a formação do súdito, e não exatamente a do cidadão - como indicavam os pensadores iluministas franceses, o que evidentemente ecoa no documento de Martim Francisco. Para Ribeiro Sanches, inclusive, nem todos teriam escola, uma vez que "filhos de jornaleiro, de pescador, de tambor, e outros ofícios vis e mui penosos, sem os quais não pode subsistir a república, quererão ficar no ofício de seus pais, se souberem ganhar a vida em outro mais honrado e menos trabalhoso?" (Sanches, s.d., p.127). Para Condorcet, a organização do ensino público dá-se como um modo de concretizar a igualdade proclamada na lei; as desigualdades econômicas seriam progressivamente minimizadas e substituídas pela única desigualdade legítima: a dos talentos. Para Martim Francisco, o discurso organiza-se de maneira próxima, sem que, todavia, ameace a situação monárquica, estamental, patrimonialista e escravocrata da realidade luso-brasileira de seu tempo, guardando o traço "moderado" que, nos anos 1820, a elite política nativista julgaria necessário manter para o controle do processo de emancipação e construção do Estado Nacional.

\section{REFERENNCIAS}

BASTOS, Maria Helena C. O ensino mútuo no Brasil (1808-1827). In: BASTOS, Maria Helena C.; FARIA FILHO, Luciano M. (Org.) A escola elementar no século XIX: o método monitorial/mútuo. Passo Fundo, RS: Ed. UPF, 1999.

CARVALHO, Laerte R. As reformas pombalinas da instrução pública. São Paulo: Saraiva; Ed. USP, 1978. 
CHARTIER: Roger. A história cultural: entre práticas e representações. Lisboa: Difel, 1990.

CONDORCET. Cinco memórias sobre a instrução pública. São Paulo: Ed. Unesp, 2008.

COSTA, A. de Souza. O centenário de Martim Francisco. Revista do Instituto Histórico e Geográfico Brasileiro, Rio de Janeiro, v.183, p.252-267, abr.-jun. 1944.

DIAS, Maria Odila L. da Silva. Aspectos da ilustração brasileira. In: A interiorização da metrópole. São Paulo: Alameda, 2005.

FALCÃO, Edgar de C. José Bonifácio, o patriarca. Sua vida e sua obra. Revista de História, São Paulo, v.28, n.55, p.151-158, 1963.

FERRONATO, Cristiano J. Construindo uma nova ordem: o debate educacional na Assembleia Constituinte de 1823. Tese (Doutorado em Educação) - UFPB. João Pessoa, 2006.

LEFEBVRE, Henri. Critique de la vie quotidienne. II - fondements d'une sociologie de la quotidienneté. Paris: L'Arche Editeur, 1961.

LIBERALLI, Carlos Henrique R. José Bonifácio, cientista e tecnologista. Revista de História, São Paulo, v.28, n.55, p.13-29, 1963.

MACHADO, Martim Francisco R. A. Memória sobre a Reforma dos Estudos da Capitania de São Paulo. Boletins da Faculdade de Filosofia, Ciências e Letras - Boletim LIII/História da Civilização Brasileira. São Paulo: USP, 1945.

MELO, Luís J. C. Parecer sobre a memória. Boletins da Faculdade de Filosofia, Ciências e Letras - Boletim LIII/História da Civilização Brasileira. São Paulo: USP, 1945.

MENDONÇA, C. S. A família do Patriarca. Revista de História, São Paulo, v.28, n.55, p.163-169, 1963.

MOACYR, Primitivo. A Instrução e o Império: subsídios para a história da educação no Brasil (1823-1835). São Paulo: Cia. Ed. Nacional, 1936.

MOREL, Marco. As transformações dos espaços públicos: imprensa, atores políticos e sociabilidades na Cidade Imperial (1820-1840). São Paulo: Hucitec, 2005.

MUNTEAL FILHO, Oswaldo. O liberalismo num outro Ocidente. Política colonial, ideias fisiocratas e reformismo mercantilista. In: GUIMARÃES, L. M. P.; PRADO, M. E. (Org.) O liberalismo no Brasil imperial: origens, conceitos e prática. Rio de Janeiro: Revan; Ed. Uerj, 2001.

NEVES, Fátima Maria. O método lancasteriano e o projeto de formação disciplinar do povo (São Paulo, 1808-1889). Tese (Doutorado em História) - Unesp. Assis, 2003.

REIS FILHO, Casemiro dos. Transplante da educação europeia no Brasil. Revista Brasileira de História da Educação, Campinas, n.3, p.115-129, jan.-jun. 2002.

RIBEIRO, José Q. A Memória de Martim Francisco sobre a Reforma dos Estudos na Capitania de São Paulo. Boletins da Faculdade de Filosofia, Ciências e Letras, Boletim LIII/História da Civilização Brasileira. São Paulo: USP, 1945.

RODRIGUES, José H. Independência: revolução e contra-revolução: a evolução política. Rio de Janeiro: Francisco Alves, 1975. 
ROUSSEAU, Jean-Jacques. Discurso sobre a origem e fundamentos da desigualdade entre os homens. São Paulo: Abril Cultural, 1983.

SANCHES, Antonio N. Ribeiro. Cartas sobre a educação da mocidade. Porto: Ed. Domingos Barreira, s.d.

SAVIANI, Dermeval. Estrutura e sistema. São Paulo: Saraiva, 1973.

SILVA, Raul de A. José Bonifácio, homem de pensamento e homem de ação. Revista de História, São Paulo, v.28, n.55, p.47-60, 1963.

VARELA, Alex G.; LOPES, Maria M. As atividades científicas do naturalista Martim Francisco Ribeiro de Andrada na capitania de São Paulo (1800-1805). História, Ciências, Saúde - Manguinhos, Rio de Janeiro, v.14, n.3, p.947-972, jul.-set. 2007.

XAVIER, Maria Elisabete S. P. Poder político e educação de elite. São Paulo: Cortez, 1980. (Coleção Educação Contemporânea).

Artigo recebido em 27 de agosto de 2012. Aprovado em 22 de outubro de 2014. 